\title{
METHODS OF DIGITIZATION OF CULTURAL HERITAGE. THE CASE STUDY OF THE TERME DI DIOCLEZIANO
}

\author{
M.G. Cianci ${ }^{1}$, M.Molinari ${ }^{1}$ \\ ${ }^{1}$ Department of Architecture, Roma Tre University, Rome (mariagrazia.cianci, matteo.molinari)@uniroma3.it
}

KEY WORDS: Archeologies, Digitalization, Stratification, Survey, Laser Scanner, Point Cloud

\begin{abstract}
:
The city of Rome looks like a succession of stratifications that have led to the formation of an architectural panorama that is unique in the world. The different eras and architectural styles that have defined the city in the two millennia of history make each of its parts unique. The punctual, areal and linear archaeological complexes unequivocally define the fabric of the city. The research investigates the theme of the analysis and representation of cultural heritage. It focuses on urban coexistences, not valued or in need of a new approach that modifies the way in which we relate. The research focuses on the way in which monumental archeologies interact with the contemporary urban fabric. The case study taken into consideration, to understand the archaeological survey methodologies for the digitization of cultural heritage, is the monumental complex of the Terme di Diocleziano in Rome. The ultimate goal is therefore to define an integrated survey methodology through which it is possible to set up a digital development work for archeologies. A development that is not limited to the two-dimensional representation of architecture but also three-dimensional, and informative at the model and geographic systems level.
\end{abstract}

\section{INTRODUCTION}

The city of Rome looks like a succession of stratifications that have led to the formation of an architectural panorama that is unique in the world. The different eras and architectural styles that have defined the city in the two millennia of history make each of its parts unique. The different architectural styles found within the urban context have led the city to elevate, assimilate or deny the architectural systems of the past. (Lanciani, 2005) The punctual, areal and linear archaeological complexes unequivocally define the fabric of the city. (Figure 01)

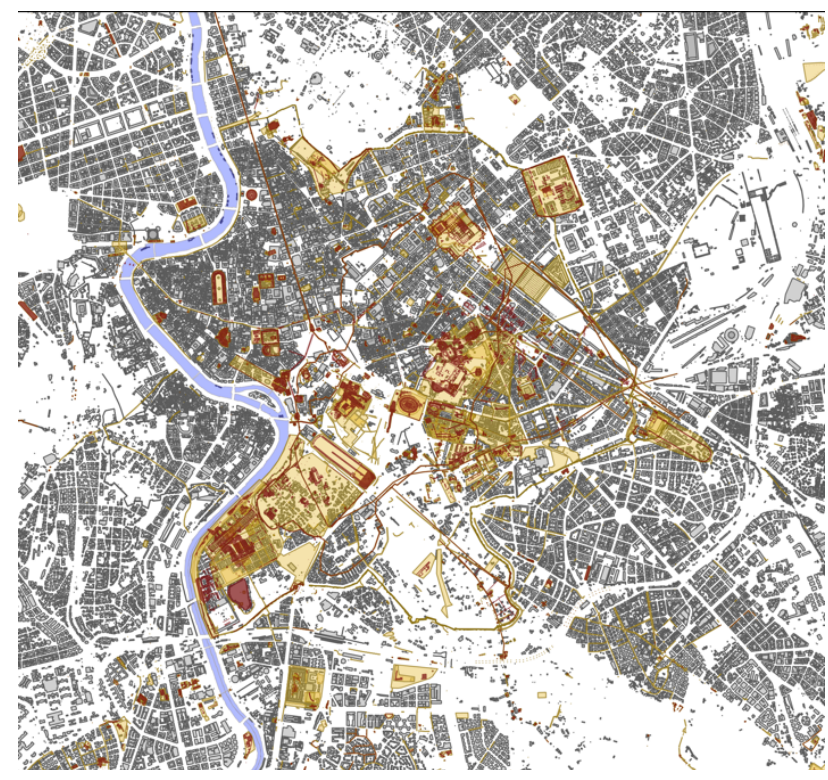

Figure 01. Traces of the Roman republican and imperial archeology superimposed on the fabric of the contemporary city. The figure is obtained through the use of a WEBGIS platform. (source ARCHEOSITAR PROJECT- MIBACT)
These artifacts not only define the urban landscape of the city, but also the very structure of some districts of the historic center of the city. The archeologies become the foundations of the buildings built in subsequent eras, defining a unique urban structure of its kind.

Two examples of great historical and cultural interest are the cellars and superfetations of Monte dei Cocci in the Testaccio district (Calisi, Molinari, 2017) and part of the Parione district which stands on the now disappeared Teatro di Pompeo. (Calisi, Cianci, 2019). In both cases, the archaeological structures are visible only in the basement floors of the buildings, where the structural, architectural, and stylistic graft between the different eras is visible.

The world of knowledge of architectural artefacts, never as in this period is concentrating scientific development towards a digitization of cultural heritage. A digitization that develops through different methodologies depending on the complexity of the object under consideration. The research investigates the theme of the analysis and representation of cultural heritage. It focuses on urban coexistences, not valued or in need of a new approach that modifies the way in which we relate. Specifically, the research focuses on the way in which monumental archeologies interact with the contemporary urban fabric. These architectures, whose peculiarities greatly differentiate them from the consolidated fabric of the city, impose a new perspective through which they must be studied, analyzed, and represented. Today's technologies allow new data collections and new analysis that open up new ways of using representation as an instrument of interdisciplinary and inter-scalar knowledge.

The digitization processes require the implementation of a specific discretization in representing archaeological elements which differs from the discretization of the simple architectural artefact. (Bartocci, Bini, 2012)

Starting from the design of the survey project, it is necessary to think from the point of view of an archaeological element with undefined geometries, subject to degradation and whose understanding is more difficult than a single architectural element. 
The ultimate goal of the research is therefore to define an integrated survey methodology through which it is possible to set up a digital development work of archeology. A development that is not limited to the two-dimensional representation of architecture but also three-dimensional, and informative at the model and geographic systems level.

\subsection{The science of architectural survey}

The science of architectural survey in the last decades has evolved hand in hand with digital technological instruments. The traditional direct survey techniques have been integrated with the most modern digital instrumental survey techniques: total station, photomodeling, laser scanner survey, drones, etc. When these two working methods are used in a two-way way, we speak of integrated survey. Through this process we tend to eliminate the error of the human component in the direct survey, obtaining a representation of reality on a 1: 1 scale. In this case the level of knowledge is reached with a greater degree of geometric, material but also geographical detail through the systems of georeferencing.

The survey project is an essential phase of any architectural and urban survey work, since it allows you to design and organize all the data acquisition operations in relation to the type of building, any critical issues of the context and the purpose of the survey. Furthermore, it acts as an element of connection between the theoretical-methodological setting phase and the practicalexecutive one, in order to have an overall control of the activities. (Docci, Maestri, 2009)

The purpose of the survey project is to outline useful ways and tools for data acquisition and to define an analytical survey scheme consisting of successive levels of study.

The objectives are:

- Design a measurement campaign in order to obtain a numerical model of the architectural organisms.

- Establish the scanning positions and the photogrammetric points to ensure a homogeneous density of points. This is done in order to contain and uniform the shadow areas, to acquire all the elements of the affected area.

- Design the scan location in oreder to understand architecture. The number must be weighted. This provides an easier digital model to elaborate.

- Ensure precise measurements compatible with the graphical error and with the purposes of the survey;

- Take all the necessary measures to allow metric stability.

- The survey of the architectural organism must allow a general understanding of its 3D spatial geometric configuration as well as of its structural articulation.

- Provide exhaustive representations deriving from this model.

- $\quad$ Provide that the elaborate drawings are also used for a three-dimensional representation of the object.

The survey project is designed to provide a solid foundation for a two-dimensional drawing, a three-dimensional representation (traditional and informative) and a georeferencing of the element using GIS tools.

\section{THE CASE STUDY}

The area of interest includes the western part of the complex of the Terme di Diocleziano, the largest in ancient Rome (298-306 AD). The baths were built to serve the Quirinale, Viminale and Esquilino districts. For the construction of the work, an entire part of the city, including villas and public houses, was demolished (Staccioli, 2005). The termal complex about $305 \times 305 \mathrm{~m}$, after the fall of the Roman Empire began to host various functions, starting a process of reuse that reaches up to the present day. The western sector (Fig. 02) is today deeply stratified by the transformations that took place following the partial abandonment (VI century AD) and then by the functional changes of some portions (Church of the Madonna degli Angeli - 1561 and annexed Certosa; Granai dell'Annona Pontificia by Gregorio XIII- 1575, enlarged by Paul V, 1609-12, and by Urban VIII, 1639; Church of Sant'Isidoro, 1754; Olearie dell'Annona Pontificia obtained by Clement XIII, 1764; seat of the National Roman Museum, 1889; Planetarium, 1928).

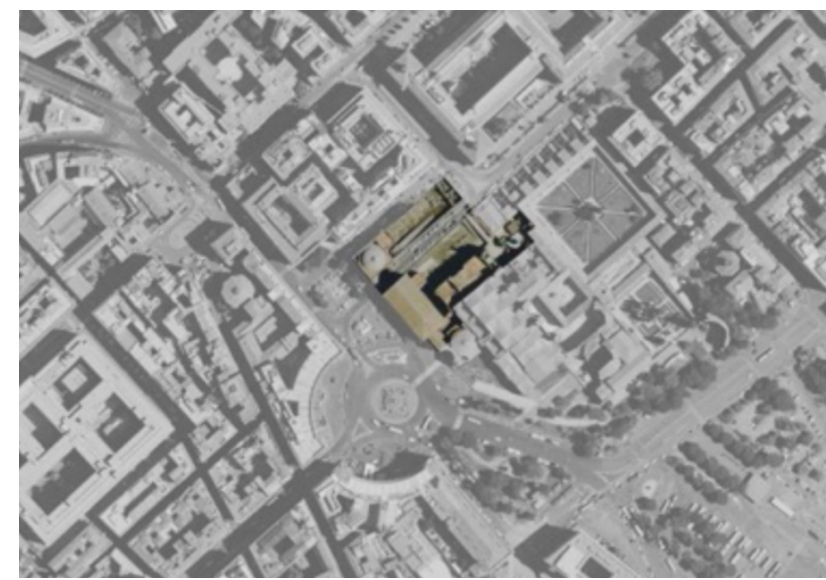

Figure 02. Identification of the area under study, through the reworking of an aerial photo. In evidence the western sector of the Terme di Diocleziano.

The area of interest, between Piazza della Repubblica, Via Parigi, Via Cernaia and the Western sector of the spa occupies an area of approximately 10,000 square meters, including:

- The passage from Michelangelo's cloister.

- The courtyard now occupied by temporary storage structures (Restoration of large marbles).

- The external area south-east of via Cernaia and related buildings (Monte Porzio Depot, Garibaldini Depot and Stamp Depot; Papal oil mills on the ground floor of the building to the south).

- The external area northwest of via Cernaia and related buildings (former Planetarium, Church of S. Isidoro).

The Baths of Diocletian are one of those archaeological complexes that are still recognizable today through an urban layout based on the original structure of the baths (Fig. 03).

The square in front, Piazza della Repubblica, originally Piazza Esedra (so called until March 20, 1953) follows with its urban structure and architectural layout of the buildings the exedra of the Terme di Diocleziano (Coaerelli, 1989). The arcades built in the period from 1887 to 1898 by Gaetano Koch want to represent the memory of the ancient structure of the Roman age. (Insolera, 2001)

To date, the complex of the Terme di Diocleziano hosts various institutions that have given new life to the archaeological spaces. The National Roman Museum was built within the perimeter of the baths, one of the most visited museums in the city of Rome. In the western sector of the baths, in addition to the former Planetarium and the Church of S. Isidoro, there is a branch of the University of Roma Tre. (Museo Nazionale Romano, Bietti Sestieri, A. M., and Italy eds., 2002) 


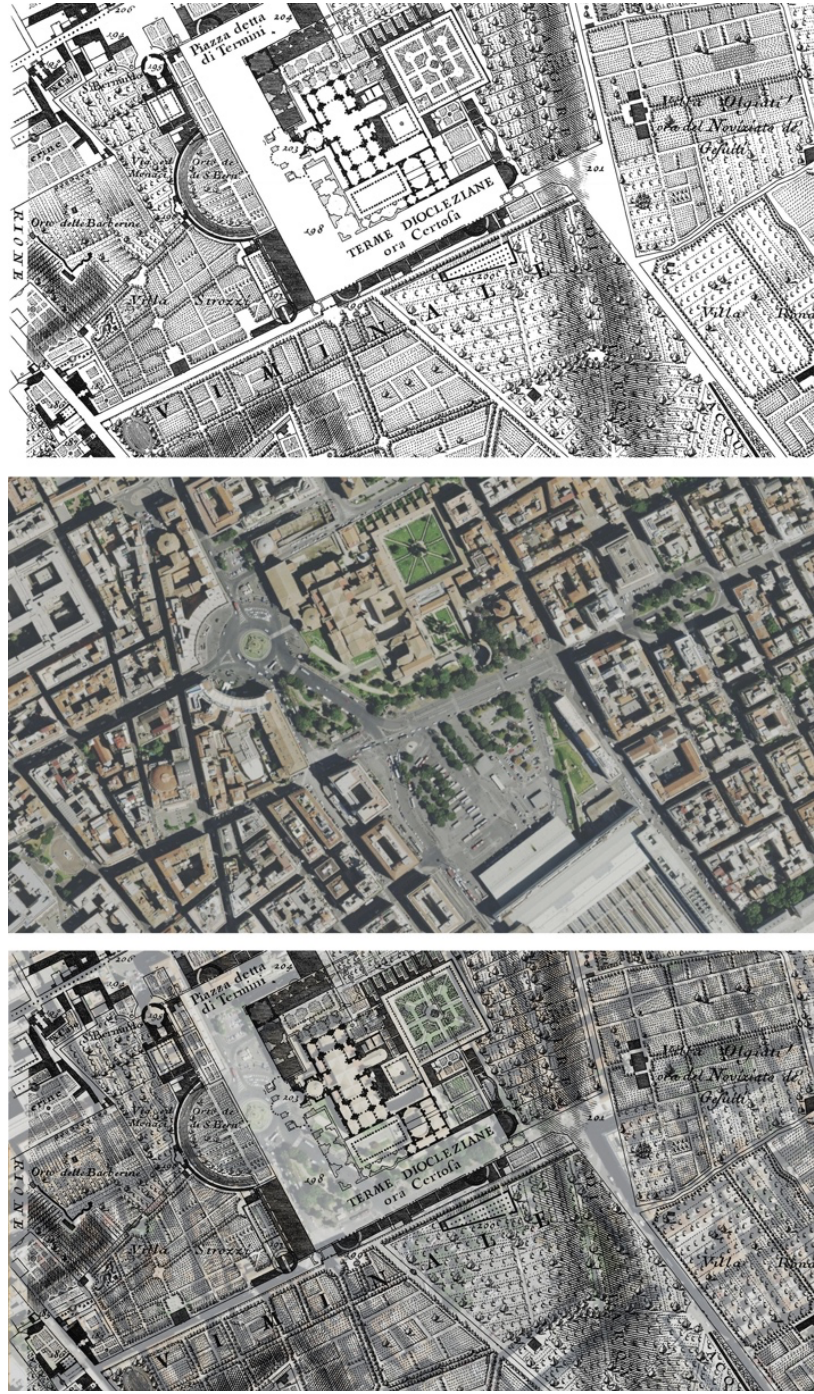

Figure 03. From top to bottom: Nolli Plan (Nolli, 2016) of the area, aerial photography (2021), superimposition of the Nolli plan with aerial photography. In the last picture is clear the connection between Piazza della Repubblica and the old structure of the baths.

\section{THE PROCESS OF DIGITALIZATION}

The digitization process of the monumental archaeological complex of the Terme di Diocleziano is set up as a typological modus operandi to be applied to urban archeology. The final aim of the research is not only to obtain a geometric survey of the artefact but also to prepare for the setting of starting files for a three-dimensional digitization, informed by archeology. Nowadays, when a survey is carried out, one cannot ignore the developments in the field of the construction industry where the standard is no longer just a two-dimensional elaborate but an "informed" three-dimensional model through which more professionals can work simultaneously. Building Information Modeling is becoming the international standard of architectural project representation methodology. (Fig.04)

BIM is the protagonist of building 4.0, the digital revolution in the architecture, engineering and construction industry. (Kymmel, 2008)

Although it has become the nerve center of this revolution, in Italy, unlike other countries in Northern Europe, we had to wait until 2016 to begin a process of legislation in the field of BIM methodology. Just 2016 was defined in Italy as the year of BIM.
Only today are public administrations beginning to understand the potential of the methodology. For this reason, the survey process implemented, regardless of the simple two-dimensional cleaning of the architectural object, has been structured in such a way that it can become the fundamental working basis for proceeding with the production of an informed digital model of the Terme di Diocleziano.

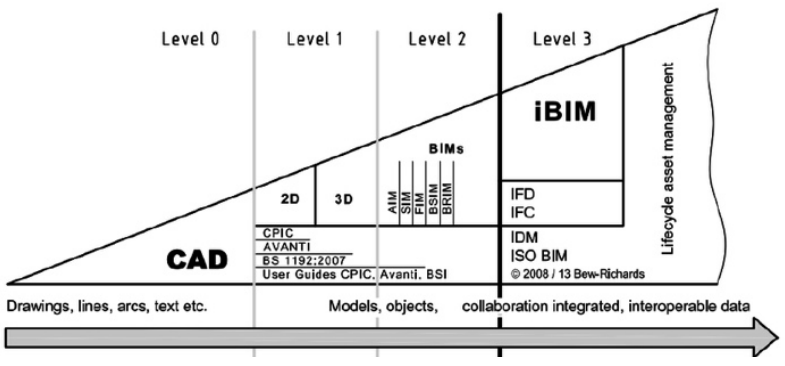

Figure 04. BIM maturity scheme (Bew, Richards, 2008). The same scheme is applicable to the development of the science of architectural survey as well as to the design of new buildings.

The digitization process of the complex was developed over a period of 4 months, during this time a strategy was developed for the approach not only to the survey but to the complete digitization of the site. The choice of instruments, the work processes, the quantity of scans have all been set in order to obtain not only a manageable digital model but also a model that allows the visualization as well as the geometric knowledge.

The starting point of these for the design of the survey campaign was a documentation of surveys carried out on the site, using direct and instrumental survey methodologies. Some of the documents dated back to the $90 \mathrm{~s}$, a period during which the former planetarium and the church of San Isidoro have been subject to a restoration project for reuse as a conference room. The implemented processes for the digitalization are: archival research for knowledge of the site through historical documentation, photographic campaign, georeferencing campaign through total station, survey campaign through laser scanner and photographic instrumentation (photomodeling), twodimensional reworking through plans and sections in the focal points understanding of the project, transposition of information for insertion into a developing GIS platform and finally preparation of files for modeling within the Heritage Building Informaion Modeling (H-BIM).

\subsection{Digitalizazion: Georefering the archeologies}

The first process for the digitization of the Terme di Diocleziano complex was the use of the total station to be able to georeference in space, what will then be the cloud of points obtained through the laser scanner survey. The importance of georeferencing and its anchoring on the national geographic network derives from the fact of positioning the detected object through coordinates. By precisely identifying the coordinates on the earth's surface of the object, the possibility of exchanging data is increased through different documents and professionalism. The procedure is completely digital and is carried out both on raster and vector files. In this case, the georeferencing process was implemented by assigning coordinates to points which will then be obtained by digitizing the site and using the point cloud.

Nowadays the information systems are a focal point in the processes of geographical reference, the presence of countless digital databases highlights the need to explain the information systems within a survey of a building, no less in the case of a relief of an archaeological complex. There is therefore the need 
to use a single recognized coordinate system at national level, to work on the same databases and simplify the georeferencing processes between the various topographic and technical maps and the surveyed elements.

Through the total station, significant points outside the complex were identified, including the surrounding buildings, in order to anchor the cloud through coordinates to a precise reference system. One of the difficulties present on the site is the simultaneous presence of various levels of altitude, delimited by discontinuous elements that made it difficult to position the instrumentation, both total station and laser scanner. (Fig.05) These markers, then taken up by laser scanner survey, have been reworked in the cloud cleaning, in order to be able to assign geographical coordinates.

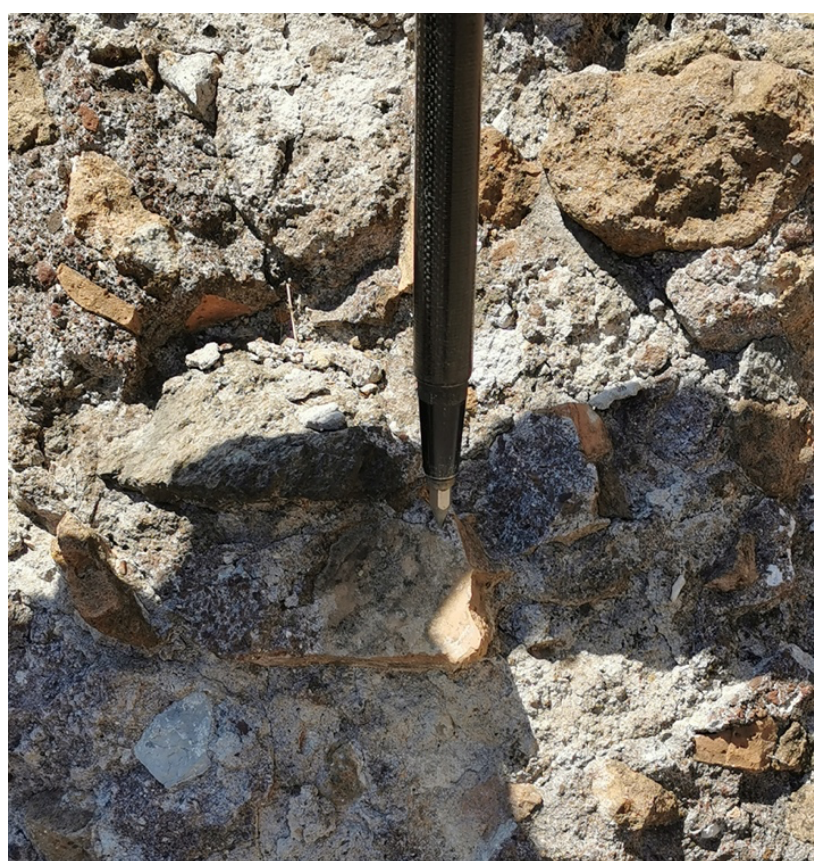

Figure 05. Positioning of the total station near archaeological substructures. The presence of discontinuous elements has increased the level of difficulty in taking points.

\subsection{Digitalization: from tangible to data}

In conjunction with the campaign via total station, it was necessary to set up the survey campaign using a laser scanner, supported by the definition of elements with a much higher degree of detail, through the use of photomodeling systems.

The laser scanner is a tool compatible with the need to have metric and timely information of the entire site, in addition to information for 2D redesign and 3D modeling. The scanner used is of the latest generation, with GPS, gyroscope, HDR camera and control tablet for on-site cloud alignment, class 1 with an accuracy of less than $2 \mathrm{~mm}$ at 10 meters. The Laser Scanner instrumentation allows you to produce a three-dimensional report formed by a cloud of points that defines the geometric and chromatic characteristics of the building surveyed.

The data acquisition phase was carried out over 10 days, through the creation of 214 laser scans with different density of points. (Fig.06) The classification given by the instrument is divided into: superhigh, high, medium and low. As the definition changes, the number of points captured by the laser instrumentation varies at an ever-greater distance. Depending on the detected environment, the range of the scans outside was between superhigh and medium. All point clouds have a densitỳ of the scans to be able to define the elements. Low-definition scans were used the in the small service rooms.

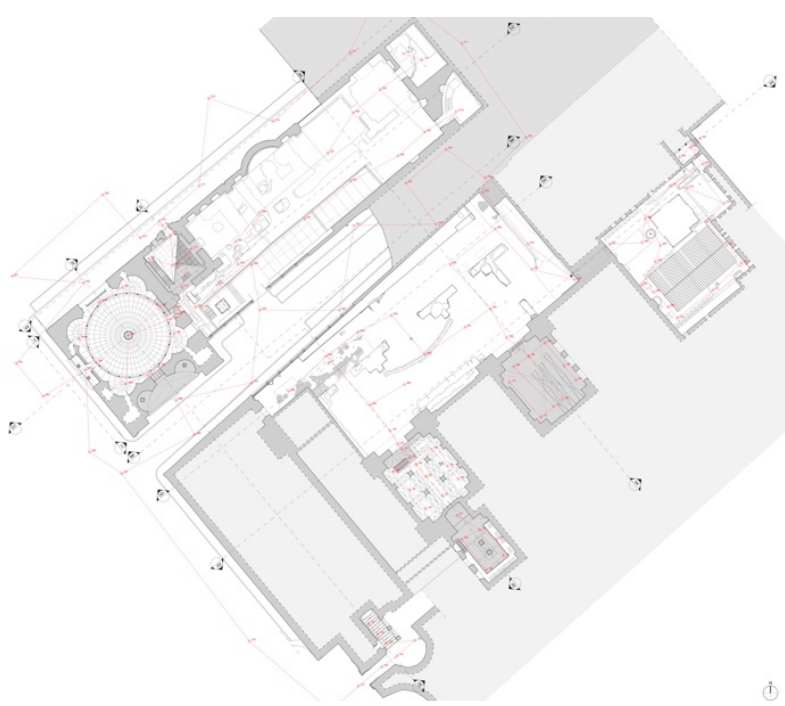

Figure 06. Identification of the laser scanner survey points relative to the L00 level detected. Depending on the detected environment, the degree of definition of the scan changes.

The point clouds are in spatial coordinates $\mathrm{X}, \mathrm{Y}, \mathrm{Z}$ with reflectance coefficients and accompanied by the RGB value. The pitch of the scanning mesh is determined according to the dimensions of the individual geometric shapes of the constructed elements, in order to guarantee a detailed survey. Scans that are carried out outside the buildings were at the same height from the ground level where possible and the height varies inside in each environment to be detected. At the same time as each Laser Scanner acquisition, photographic images were acquired using a Laser Scanner equipped with a ccd / HDR sensor or with external cameras from the same scanning position; the images entirely cover the area detected by the laser scanner. (Fig. 07)

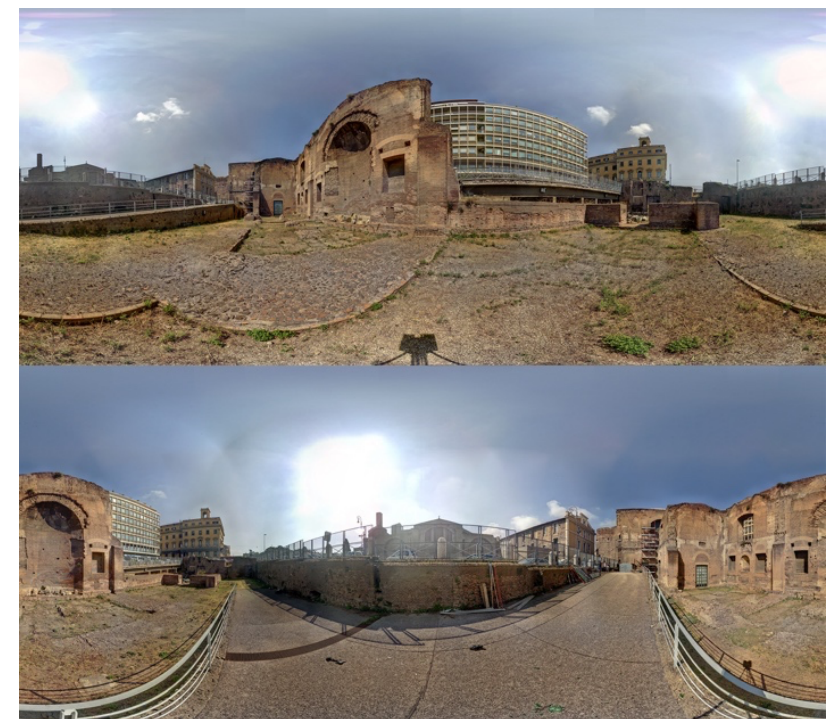

Figure 07. Panoramic HDRI image, made during the survey campaign by laser scanner.

The images have the same center of grip as that of the laser scanner (without parallax) in order to ensure the correct attribution of the RGB data to each 3D point. 
Given the distinct materiality of the architectural artifact, it was necessary to integrate the survey campaign using a laser scanner with a technique called photomodeling. Photomodeling, a survey technique that has now become the standard, through Structure from Motion (SfM) techniques, with which it is possible to reconstruct the 3D geometries through the association of two or more photos in which homologous points are recognized, tahat is easily recognizable points. The different software developed fot photomodelling use pairs of frames to recognize the homologous points of the photographs to build first a sparse cloud and then a dense cloud of points. (De Luca, 2011) The points are associated based on the chromatic values and the position in which the photographs are taken. The substantial difference with respect to laser scanner shooting is that the detected object is not in 1:1 scale and that the definition and accuracy of the shot depends on the mode in which the photographs are taken, the resolution of the images and the lighting conditions. The processing programs used to implement this survey technique use all the metadata of the photographs for the association of homologous points. The use of this technique has allowed us to define with a greater degree of detail not only the materiality of the artifact but also some elements of detail such as the external moldings of the church of Sant Isidoro. The direct survey has entered the field in this case, for the taking of measurements and the relative scaling of the model created. The measurements taken were then compared with the point cloud, and where necessary the two models through a file interchange process were integrated. In some cases, however, it was not necessary to integrate the two models, as the model recorded by photomodeling had a degree of detail too high to be integrated with the model obtained through the point cloud.

After the data acquisition phase, a data processing phase was carried out in which we proceeded with the alignment of the laser scanner scans, the elimination of all the disturbing elements present in the individual scans (cloud cleaning), this was the in order to obtain an integral numerical model of the area and of the architectural artefact, i.e. the point cloud in .rep and in .e57 format. (Fig. 08) In this operational phase the numerical model was also elaborated with the photogrammetric method starting from the photographic images, which was then integrated into the point cloud model created by Laser Scanner.

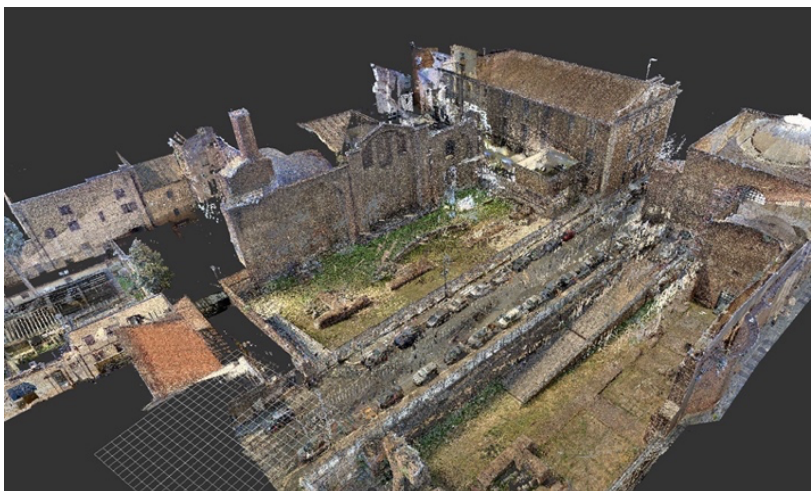

Figure 08. Image of the point cloud cleaned up, after eliminating all the context not relevant to the survey project and the elements that obstructed the process of knowing the artifact. The point size in the image is 1 . This way the visualization of the model is clearer.

The point cloud was the starting point for the digitalization of the survey of the Terme di Diocleziano, reworked using CAD software. Given the extension of the site and the high number of scans, it was necessary to create a second decimated point cloud starting from the first one. The decimation of the point cloud is a necessary process in these survey situations, as by not losing the required detail it reduces the number of points and allows you to work more easily in two-dimensional processing software without losing the degree of detail.

The decimated point cloud made it possible not to lose the fundamental geometric data, leaving a precision in the twodimensional drawing of not less than $2.5 \mathrm{~cm}$.

The decimated point cloud was then used for the redesign and production of the two-dimensional drawings, the non-decimated one, with a higher resolution, was then used to draw up the orthophotoplanes. This choice was dictated by the definition of the orthophotoplanes, using the decimated point cloud, where the number of points had been significantly reduced, would have presupposed the obtaining of two-dimensional raster drawings that did not quite truthfully reflect the materiality of archeology. The two-dimensional geometric metric restitution was implemented with a degree of detail, on a scale of 1:50. The point cloud object is in effect a silent digitization of reality, reproducing in 1:1 scale everything that the instruments are able to detect. In order to obtain digital work bases, it is necessary to proceed as a first approach to a transposition of the artifact detected by operating a discretization process. Through the twodimensional vectorization of the case study, focal points of the site were identified, which, with the support of the point cloud, made it possible to perfectly understand the archaeological complex in three dimensions.

Two planimetric drawings have been created that define the environments that are objects of the survey and nine significant sections for understanding the western sector of the Terme di Diocleziano in elevation. The nine sections have been created in such a way as to give an overall picture of knowledge of the site both at a topographical level and at the level of three-dimensional development of the built environments. Some elements, such as the temporary structures of the construction site, have not been digitized. In one of the classrooms there was a loft in metal tubes that would have been demolished, for this reason it too was not the subject of relief.

During the graphic rendering, it was decided to use the floor of the Sala Ottagona (Octagonal Room) as the relative survey height 0.00. (Fig. 09)

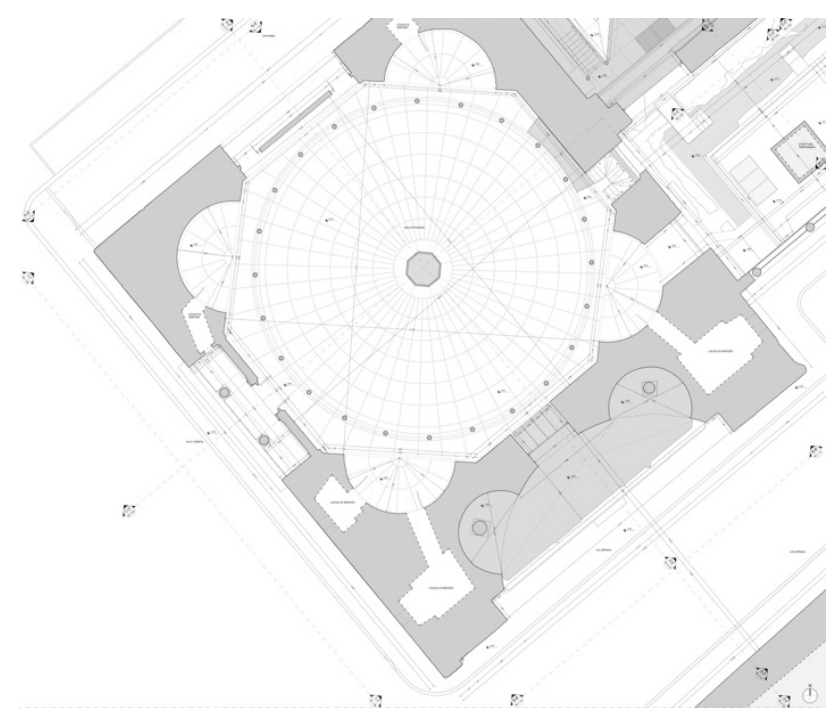

Figure 09. Plan of level 00 of the Sala Ottagona. Since the floor is horizontal, it was chosen as the relative height 0 . All the dimensions within the survey therefore refer to the internal floor of the room. The slope inside the Sala is less than $1 \%$ starting from the center. 
The choice derives from the contemporary architectural definition of the room, which stands as a level floor with a negligible slope, a key feature within a site with a variable horizontal plane. The coexistence of significant height jumps between the various parts of the site, and the need to represent them in an exhaustive manner, has forced the use of a horizontal cutting plane for the preparation of floor plans not at a height of one meter from the ground. In this way it was possible to relate several environments without creating staggered sectional plants. (Fig. 10)

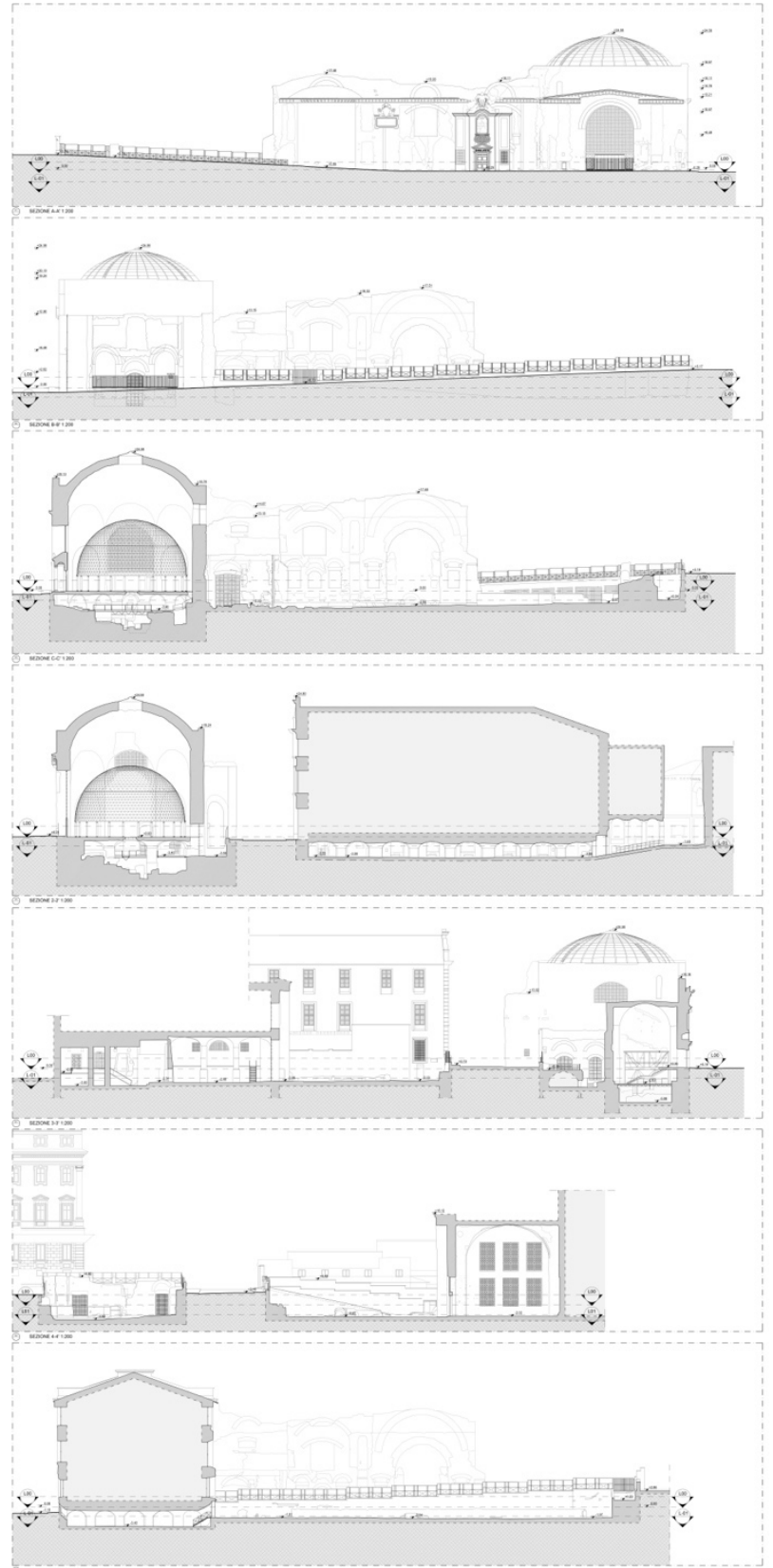

Figure 10. Seven of the nine sections made for an elevation understanding of the site. The elevations shown refer to the 0 elevation of the octagonal classroom. The sections in the image are represented on a scale of 1:200 and are aimed at the general understanding of the site.

The inability to access some areas adjacent to the survey area limit did not allow in some cases to understand the wall thickness of some architectural elements. For this reason, we have chosen to work by analogy, with respect to the known and detected elements. In some cases, the historical documents found were of support to understand some architectural elements that in the actual state were degraded and not easy to understand.

To define the materiality of the architectural artifact, both in elevation and in plan, it was decided to use orthophotoplanes superimposed on some elements of the two-dimensional CAD design. The two-dimensional drawing in elevation and in plan has highlighted the discontinuity points of the material, the elements of notable decay, in order to give a clear reading of the twodimensional drawings produced. Furthermore, this approach of dividing material and decay elements was conceived as a basis for the modeling process. The identification of thematic areas and not specific elements allows, during the modeling phase, to divide the three-dimensional element more easily and to assign precise data to it.

The point cloud itself is a three-dimensional model which, as such, can be used for all canonical representation methods. Once the cutting planes of the point cloud have been identified, corresponding exactly to the 9 section lines identified in the plan, the tools allow you to exactly reconstruct the orthogonal 3D projections, whether they are plans or elevations.

The still vector point cloud is oriented according to the needs and then printed. In this process, the three-dimensionality of the point cloud is flattened into a single raster image to aid in the material relief.

The orthophotoplane defines the material that makes up the architectural element and its chromaticity and integrating it with the sectioned elements of the two-dimensional drawing it recounts the volume in the most appropriate way.

The orthophotoplanes were extrapolated from the undecimated point cloud, in order to obtain a raster image with a higher number of points and therefore a more defined material detail. In this way, the geometric and material changes were defined in the technical drawings, but the material definition derives from the orthophotoplane. (Fig. 11)

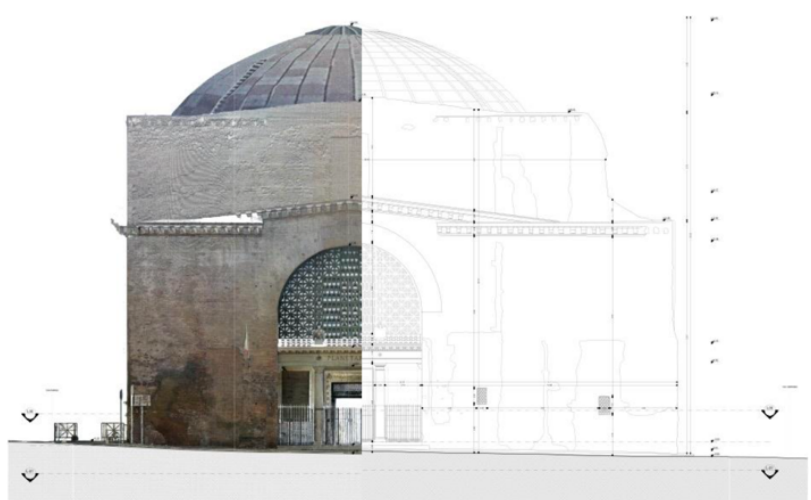

Figure 11. On the left the orthophotoplane of section 1-1' obtained from the point cloud, on the right the two-dimensional vector elaboration, traced in CAD directly on the point cloud and projecting the design on a single projection plane.

The drafting of the two-dimensional drawings originated from dissecting the dense point cloud created in the CAD context. For this reason all the drawings are not flat in space without a reference of global coordinates, but are georeferenced in space. Georeferencing is therefore not limited to the planimetric drawings but also to those in elevation. The plans are thought to be positioned in space, and not only vary according to the $X Y$ reference systems but also take into account the $Z$ variant. The same happens for the sections, not flattened on the $\mathrm{XY}$ plane but 
use an $\mathrm{XZ}$ reference system in order to leave the documents positioned in the correct place. The exchange phase, twodimensional printing, on the other hand, saw the use of specific UCS to allow a coplanar reading of all the documents. All the annotative attributes aimed at a scientific reading of the papers have been assigned to those UCS.

This strategy is a winner from several points of view, despite increasing the difficulty in managing files. In fact, the possibility of using the CAD files created in conjunction with the point cloud for the creation of an informed three-dimensional model allows you to import all the documents in a single environment and find them in the correct position. In this way, whether you choose to create a geometric model devoid of information or a BIM model, (the final aim of the research) all the drawings perfectly overlap the point cloud in the three georeferenced dimensions. This allows to facilitate not only the modeling process but also the understanding of the architecture.

\section{CONCLUSIONS AND FUTURE DEVELOPMENT}

The research theme arises from a reflection on the theme of information associated with architectural artefacts.

Design in the last decade has been changing, focusing on the drafting of projects that go beyond simple design, associating each element with metadata. Through this process, the process of integrated design has been developed, a design approach that sees all the information seen in a single area, avoiding a partialization of the information. This process and the preparation of a digital model containing all the design information, allows the representation of the building beyond the three dimensions, defining what are called the seven dimensions of Building Information Modeling.

This process cannot become a best practice only for new constructions or for the retrofitting of twentieth century buildings, but must also begin to take into consideration the historical-cultural heritage of the contemporary city. Nationally, these BIM declination experiments are taking place on symbolic architectures of some eras, defining what literature defines Heritage Building Information Modeling. (Arayici, 2017)

Like the surveyor, the architectural survey document reference (Carta del Rilievo Architettonico) highlights the need to make use of new technologies to draw up an integrated, informed survey, and that the result obtained can be shared by several professionals. (AA. VV., 2019)

Representation is no longer a static aspect of architecture but takes on a form of dynamism that evolves as the conditions of the building change. Consequently, the science of survey must adapt to this approach, carrying out analysis and transpositions that take into account not only a geometric transposition but also a threedimensional vision enriched by the metadata of the object taken into account. The purpose of the survey project is to outline useful ways and tools for data acquisition and to define an analytical survey scheme consisting of successive levels of study. The survey results represent a starting point and an important knowledge and support tool for thematic and diagnostic analyzes on building. (Cianci, Colaceci, 2017)

The research presented, which focuses on the geometric survey of the Terme di Diocleziano, is part of a broader research that focuses on the digitization processes of urban archeology in Rome. The final aim is not to obtain mute digital surveys of architectural and archaeological elements within the urban fabric of the city of Rome, but to obtain an informed didactic digital database that digitally describes the stratification of the city of Rome. This study presented is the first aimed at outlining a methodological basis for the digitization of archaeological complexes and the related cleaning in the context of Information
Modeling. The geometric complexity and the large surface area require various precautions in this process, in particular because there are no historical architectures or historic buildings ranging from the late nineteenth to the twentieth century but archaeological remains. (Fig.12)

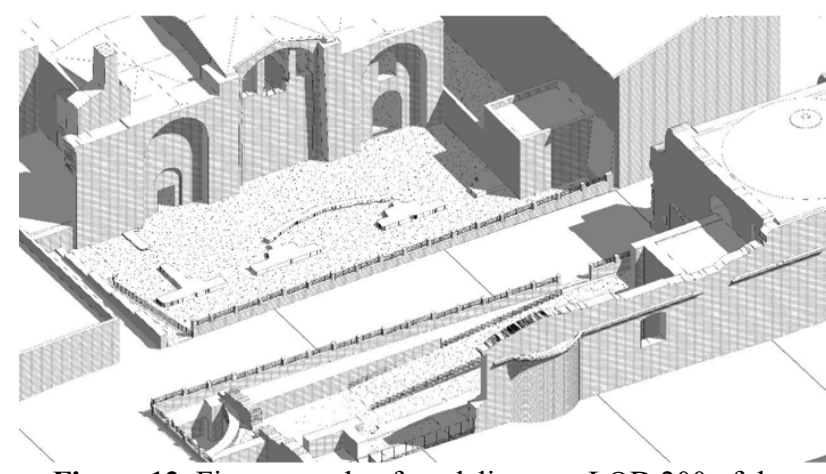

Figure 12. First example of modeling to a LOD 200 of the Diocletian Baths complex, starting from the two-dimensional drawings and with integration of the point cloud created during the survey phase

The methods of modeling, scanning and knowledge are the same but at the same diametrically opposed. The discipline of H-BIM, like that of BIM, is a method of representation in continuous development and highly dependent on the software resources currently available on the market. The scientific publications, the conferences held on the subject, highlight how different approaches are continuously developed, adapting to what the constantly evolving technologies allow to do.

$\mathrm{H}-\mathrm{BIM}$ in particular regarding urban archeology is a tool aimed at the management, maintenance and restoration of existing elements, therefore it is aimed at a "public" such as the public administration, whose resources are in some cases limited. In an H-BIM approach, the model, obtained through a careful and critical rereading of the survey data in a broad sense (not only geometric), constitutes a real "content index", which can be consulted in real time to reach every single component of the building represented as follows: geometry, historical phase, materials, state of decay, interventions hypothesized by the designer or actually carried out. This is only a non-exhaustive list of the amount of data that can be entered and consulted in the digital archive. They will accompany the building in what remains of its life cycle and will greatly facilitate the task of those who will have to take care of its protection and future restoration. Given the difficulty in retrieving the data, as there is rarely the certainty of the non-visible components or the characteristics with which they have been implemented and maintained over time, it is important to underline that the digital archive and the model connected to it must be modified and integrated whenever there is the possibility of discovering new information. It is therefore necessary to set up an information protocol in such a way as to ensure the implementation of data that can be constantly collected.

In the field of historical construction, the phase of knowledge of what exists, from a geometric, constructive, technological, historical point of view, etc. is fundamental. These data constitute the starting point for the creation of any modeling. The survey results represent a starting point and an important knowledge and support tool for thematic and diagnostic analyzes on buildings. This article therefore presented the methodological starting point in an approach to the integrated survey of an urban archeology. The data presented were processed in such a way as to allow a traditional use, two-dimensional reading of the architectural 
element, but also a use for the three-dimensional and informed modeling of the building.

The discretization implemented has selected geometric information in order to simplify its representation but without losing its initial geometric meaning. When working with a point cloud, as mentioned in the previous paragraphs, the discretization process becomes more difficult, the operator, the architect, the surveyor, come into possession of 1:1 scale data and only the acquired skills allow to discern basic geometric data from negligible ones.

\section{ACKNOWLEDGEMENTS}

The survey project is part of the convention between the Department of Architecture and Studio Feiffer \& Raimondi / National Roman Museum.

Scientific coordinator: Maria Grazia Cianci.

Participating professors and researchers: Maria Grazia Cianci, Daniele Calisi, Sara Colaceci, Matteo Molinari, Michela Schiaroli.

\section{REFERENCES}

Arayici, Y., Counsell, J., Mahdjoubi, L., Nagy, G., Hawwās, S. Z., e Dweidar, K. eds., 2017: Heritage building information modelling. New York: Routledge/Taylor \& Francis Group

Bertocci, S., Bini, M. (2012) Manuale di rilievo architettonico e urbano. Torino: Città studi

Bew, M., Richards, M.: 2008, Bew-Richards BIM Maturity Model

Cianci M.G., Colaceci S., 2017: The methodology of interpreting and promoting historical heritage: the Maxentius complex on the Appia Antica, in DISEGNARECON. Archeological Drawing, vol. 10 n. 19, dicembre 2017, Università dell'Aquila, L'Aquila 2017, ISSN 1828-5961, pp. 10.1-10.19

Calisi D., Cianci M.G. 2019: La città stratificata. Largo dei Librari a Roma. In RIFLESSIONI. L'arte del disegno/il disegno dell'arte (REFLECTIONS. The art of drawings/the drawing of art), Belardi P. (a cura di), Atti del $41^{\circ}$ Convegno internazionale dei docenti delle discipline della rappresentazione, XVI Congresso dell'Unione Italiana per il Disegno (Perugia 19-21 Settembre 2019), Gangemi Editore spa, Roma 2019, ISBN 97888-492-3762-7, ISSN 2611-4062 pp. 471-480

Calisi D., Molinari M. 2017: Il rilievo urbano in ambiti archeologici. La fotomodellazione applicata all'analisi dimensionale e materica delle sostruzioni alle pendici del Monte Testaccio. In REPRESENTANDO IDEAS, GENERANDO SOLUCIONES, Bombassei E. (a cura di), atti del XV Congreso Nacional de Profesores de Expresión Gráfica en Ingeniería Arquitectura y Carreras Afines (La Pampa, 12-14 ottobre 2017), UniRío editora, Río Cuarto (Argentina) 2017, ISBN 978-987688-244-6, pp. $121-126$

Coarelli, F. (1989) Guida archeologica di Roma. 5. ed. aggiornata. Milano: Mondadori

De Luca, L., 2011: La fotomodellazione architettonica: rilievo, modellazione, rappresentazione di edifici a partire da fotografie. Palermo: Flaccovio
Docci, M., Maestri, D., 2009: Manuale di rilevamento architettonico e urbano. Nuova ed. ampliata. Roma: Editori Laterza

Kymmell, W., 2008: Building information modeling: planning e managing construction projects with $4 D C A D$ e simulations. New York: McGraw-Hill

Insolera I., 2001: Roma moderna. Un secolo di storia urbanistica. 1870-1970, Roma, Einaudi Editore

Lanciani, R. A., 2005: L' antica Roma: la ricostruzione della città antica sulla base dei ritrovamenti archeologici di fine Ottocento, dai fori ai templi, ai palazzi imperiali. Roma: Newton \& Compton

Museo Nazionale Romano, Bietti Sestieri, A. M., and Italy eds., 2002: Museo nazionale romano Terme di Diocleziano. Milano: Electa

Nolli, G. B., 2016: Nuova pianta di Roma data in luce da Giambattista Nolli l'anno 1748, Intra Moenia, Roma, Italia

Staccioli R. A., 2005: Acquedotti, fontane e terme di Roma antica, Roma, Newton \& Compton, 2005.

AA.VV., 1999: Verso la "Carta del Rilievo Architettonico" testo di base per la definizione dei temi. The document was disclosed on the occasion of the International Study Seminar "Gli strumenti di conoscenza per il progetto di restauro" (Val-montone, settembre 1999) 